\title{
PERCEPÇÃO-PRODUÇÃO DA FRICATIVA INTERDENTAL SURDA DO INGLÊS /O/ TENDO COMO SUPORTE O DESENVOLVIMENTO DA CONSCIÊNCIA FONOLÓGICA
}

\author{
Anilda Costa Alves* \\ Leônidas José da Silva Jr**
}

\begin{abstract}
Resumo: No ensino de uma segunda língua é importante o reconhecimento de algumas diferenças existentes entre inventário fonêmico da língua materna e da língua-alvo, como também a existência de algumas mudanças na maneira como esses fonemas são estruturados. O não entendimento disto pode comprometer a percepção de determinados segmentos, visto que o aprendiz tem como base para entender a língua-alvo apenas o seu inventário fonêmico da língua materna. Este trabalho tem como objetivo analisar a eficácia do desenvolvimento da consciência fonológica no nível fonêmico no processo de percepção-produção da fricativa interdental surda por falantes brasileiros do inglês como segunda língua.
\end{abstract}

Palavras-chave: Fricativa interdental surda $/ \theta /$. Consciência fonológica. Ensino do inglês como segunda língua.

\begin{abstract}
In the teaching of a second language, it is important to recognize some differences between the phonemic inventory of the mother tongue and the target language, as well as the existence of some changes in the way these phonemes are structured. Misunderstanding this inventory may compromise the perception of certain segments because the learner is based on understanding only the phonemic inventory of the mother tongue. This paper aims to analyze the efficacy of the development of phonological awareness at the phonemic level in the process of perceived production of the voiceless interdental fricative $/ \theta /$ by Brazilian speakers of English as a second language.
\end{abstract}

Keywords: Voiceless interdental fricative / $/$ /. Phonological awareness. Teaching of English as a second language.

\section{Introdução}

Visto que cada língua apresenta uma estrutura específica, independente da língua a qual se esteja trabalhando em sala de aula, é muito importante a utilização da consciência linguística em seus aspectos fonético-fonológicos para a obtenção de resultados mais eficazes - tanto na comunicação como nas trocas conversacionais durante a produção dos atos de fala na segunda língua/língua estrangeira (doravante, L2) - do que os até agora apresentados pelos alunos ao fim do Ensino Médio; em que as abordagens utilizadas no ambiente escolar se debruçam quase que unicamente sobre a morfossintaxe das línguas e não sobre seu uso oral (cf. WIDDOWSON, 1978).

A consciência fonológica, segundo Alves (2012), equivale a uma reflexão que acontece de forma consciente sobre os sons que compõem uma língua e a partir dessa reflexão, a manipulação de seus elementos. Ao iniciar os estudos em uma L2, é importante que esta consciência acerca dos sons da(s) língua(s) possa ser desenvolvida visto que indivíduos que já possuem a fonologia da língua materna (doravante, L1) estruturada tendem a transferir para a L2 padrões da L1. A esse tratamento da L2 seguindo os mesmos padrões da L1, denomina-se transferência fonológica (TF).

\footnotetext{
* Mestranda do PROLING (UFPB), bolsista CAPES. Endereço eletrônico: anildacosta16@gmail.com

** Professor adjunto e pesquisador-coordenador do GeFone no Departamento de Letras - CH/UEPB/CAPES. Endereço eletrônico: leonidas.silvajr@gmail.com
} 
Ao responder a questões sobre o ensino da L2 de modo a evitar as TFs, Ramos (2009) relata que essas transferências são processos naturais e que não se restringem apenas à fonologia da língua, antes, se estendem aos aspectos sintáticos e morfológicos.

Ramos (op. cit.) aponta como um dos causadores das dificuldades dos alunos em reconhecer as distinções fonológicas das línguas, o fato da pouca exposição ao novo idioma. Muitas vezes, os alunos têm dificuldades em compreender a fonologia da própria língua e esta compreensão, nas relações interlínguas, torna-se tarefa mais árdua. Em parte, os próprios alunos classificam como desnecessário o ensino de um novo idioma como o inglês, pelo fato de acreditarem não ter utilidade para suas vidas. Tal fato nos mostra dois aspectos fundamentais na tentativa de obter mais êxito no ensino. Primeiro, que é importante que o aluno sinta-se motivado em aprender o novo idioma e segundo, que ele seja capaz de perceber que ambos os sistemas apresentam distinções importantes de serem entendidas para que sua competência comunicativa no tocante à oralidade seja bem sucedida.

O fato de os alunos não compreenderem que pode haver distinções entre as línguas leva a hipótese de que os padrões fonológicos de sua língua são universais e isso os leva a não diferenciarem fonemas ou estruturas silábicas que diferem de sua L1, corroborando assim as palavras de Polivanov (1931) quando afirma que a percepção acústica se dá baseada na experiência linguística que o falante possui.

Alves (2012) destaca ainda que um aprendiz capaz de operar sobre os sons da L1 poderá fazer o mesmo na L2 desde que se mostre capaz de perceber as diferenças existentes entre ambos os sistemas. Vale salientar que o pouco tempo de exposição do aprendiz e a não atenção aos aspectos fonético-fonológicos dessa nova língua por parte do professor, tendem a não favorecer esse reconhecimento de forma consciente. Mesmo havendo certos estranhamentos por parte do aprendiz diante de uma língua que não seja sua L1, determinados parâmetros carecem de um pouco mais de atenção pelo fato de apresentarem certa complexidade.

Será que um ensino pautado não apenas nos aspectos morfossintáticos da L2, porém antes, levando ao aprendiz a oportunidade de entender que os parâmetros de sua língua não são universais, poderia favorecer um ensino mais próximo, ou ao menos, consciente de que cada língua apresenta suas próprias peculiaridades?

Objetivamos, desta forma, analisar os efeitos da aplicação de atividades que contemplam o desenvolvimento da consciência fonológica com alunos brasileiros de uma turma de nono ano (ensino regular) de uma escola particular da cidade de Guarabira-PB. Os resultados obtidos comprovam a eficácia de uma abordagem pautada no desenvolvimento fonético-fonológico da L2, como também servem como ponte para mais pesquisas na área, pois, percebe-se ainda uma precarização de tais abordagens na realidade escolar.

\section{Fundamentação teórica}

Durante a seção 2, definiremos conceitos relativos à consciência fonológica em uma visão panorâmica bem como, sua implementação nas características fonético-fonológicas de segmentos da L2 e modelos de exercícios que potencializem a consciência dos sons nesta língua estrangeira. Por fim, com um foco mais estreito, veremos como se dá o processo de consciência fonológica da fricativa interdental surda; apontando contrastes fonéticos com sons da L1. 


\subsection{Consciência fonológica}

Além da capacidade que o indivíduo possui de compreender o significado ao qual uma palavra remete ou as diversas interpretações que podem ser dadas aos enunciados, a depender do contexto e até da entonação empregadas pelo interlocutor num momento de diálogo, o ser humano possui ainda a capacidade de se debruçar sobre a forma como o código de sua língua é estruturado de forma consciente.

Este ato denominado consciência fonológica (doravante, CF), segundo Alves (2012), envolve duas etapas: reflexão e manipulação. Para o autor, a reflexão envolve a capacidade de compreender a maneira como os sons podem ser organizados na língua e a manipulação é a capacidade de operar sobre esses sons, desenvolvendo atividades como apagamento, inserção, transposição etc.

Ressalta ainda que a CF é um conceito muito amplo, não correspondendo apenas a um nível de habilidades, acontece num continuum de complexidade, que envolve desde atividades que manipulam sobre a sílaba até o nível mais complexo, o fonêmico.

\subsection{Consciência dos aspectos fonético-fonológicos da L2}

Assim como na L1, Alves (2012) aponta a indissociabilidade das etapas que comprovam que um indivíduo é consciente fonologicamente em L2; a reflexão e a manipulação. $\mathrm{O}$ autor destaca que diante de uma língua como o inglês, que apresenta fonemas diferentes do português brasileiro (doravante, $\mathrm{PB}$ ) e apresenta ainda uma organização silábica distinta, o indivíduo precisa se mostrar conhecedor, de forma implícita ou explícita, de tais aspectos para que suas produções sejam inteligíveis a qualquer falante de inglês; seja L1 ou L2 na busca de uma comunicação bem sucedida. Esta relação fonologicamente consciente traz ao falante da L2 uma melhoria durante a mediação com outros interlocutores também de inglês como L2 - nos aspectos diatópicos e diastráticos da fala - e aumenta os níveis de compreensão e produção durante a exposição oral com falantes nativos de inglês (cf. JENKINS, 2007, 2000; KRAMSCH, 1993).

Dessa forma, Alves (op. cit.) salienta que para que haja uma manipulação eficaz desses sons da L2 o aprendiz necessita antes refletir acerca das diferenças dos dois sistemas fonológicos. No processo de reflexão sobre o sistema da língua-alvo, o autor afirma que o aprendiz reconhece os estágios de sua dificuldade em estar mais próximo ou não de um falar nativo.

Assim como na L1, a CF em L2 se desenvolve em níveis que vão desde o reconhecimento dos fonemas que compõem a língua-alvo e não estão presentes na L1 ao reconhecimento dos padrões silábicos distintos e rimas. Sobre estes, aprendizes brasileiros tendem a se deixar levar pela regularidade grafo-fônica do português, sendo o inglês - em contrapartida - uma língua que não mantém essa mesma regularidade, por exemplo, missed [mist], list [list] em que há equivalências de padrões silábicos e rimas, mas não há equivalências ortográficas.

Por outro lado, no PB, podemos observar um processo chamado de distribuição complementar ${ }^{2}$ em determinados ambientes fonológicos que não ocorrem em inglês, por exemplo, as oclusivas alveolares $[\mathrm{t}, \mathrm{d}]$ que podem ser realizadas como africadas palatais $\left[\mathrm{t} \int\right.$,

\footnotetext{
${ }^{2}$ Segundo Hayes (2009), a distribuição complementar acontece quando: em dois sons (alofones) de um mesmo arquifonema, um não ocorre em um mesmo ambiente que outro ocorre sem mudança de sentido, isto é, se alternam sem alterar o significado da palavra. Por exemplo, no dialeto paulistano, na palavra "porta", o som da vibrante alveolar $[\mathrm{r}]$ ocorre no lugar da fricativa uvular $[\mathrm{r}]$, ou seja, po[в]ta se realiza como, po[r]ta.
} 
d3] respectivamente diante da vogal oral alta [i], por exemplo, a produção da palavra "tia" em alguns dialetos do PB podem variar entre [tia] e [t $\mathrm{fia}$ ]. Igualmente na palavra "dia" variando entre [dia] e [dzia] sem alterar o significado da palavra. Em inglês essa troca acarreta em significados diferentes, por exemplo, cat (gato) [ $\mathrm{k}^{\mathrm{h}}$ æt $]$ e catch (pegar) [ $\left.\mathrm{k}^{\mathrm{h}} æ \mathrm{t} f\right]$.

Embora o indivíduo se mostre consciente das distinções acima apresentadas, não implica dizer que haverá uso espontâneo de tais aspectos da L2. O papel do professor aqui defendido é a não discriminação dessas diferenças sistemáticas, pois a partir desse conhecimento o indivíduo é capaz de entender suas próprias dificuldades no tratamento de uma L2.

Como forma de mostrar que o trabalho abordando o desenvolvimento da $\mathrm{CF}$ não apresenta complexidades, Alves (op. cit.) apresenta exemplos de exercícios que estimulam cada nível. Ilustraremos alguns desses exemplos nas tabelas abaixo:

Tabela 1 - Identificação de rimas em L2

IDENTIFICAÇÃO DE RIMAS EM PALAVRAS DA L2

Objetivo: ao realizar esta atividade, o aluno demonstrará sua capacidade de identificar rimas na L2. O aprendiz deverá reconhecer que palavras que rimam não necessariamente possuem grafia semelhante (o que é o caso de missed e fist, por exemplo).

\begin{tabular}{|c|c|}
\hline \multicolumn{2}{|c|}{ ATIVIDADE } \\
\hline Que palavra rima com fact? & tract - fax - at \\
\hline Que palavra rima com missed? & licit - fist - amazed \\
\hline
\end{tabular}

Fonte: Alves (2012, p. 179).

Tabela 2 - Reconhecimento fonêmico em L2

RECONHECIMENTO DOS FONEMAS

Objetivo: o aluno deverá apontar a diferença entre dois sons que não pertencem ao inventário fonológico da sua L1 (questões ' $a$ ', 'b' e 'c'). O aluno deverá, também, diferenciar os sons de sua língua materna daqueles que pertencem apenas ao inventário fonológico da língua-alvo (questões 'd' e 'e').

\begin{tabular}{|c|c|c|}
\hline \multicolumn{3}{|c|}{ ATIVIDADE } \\
\hline - $\quad$ Palavras & $\mathrm{e}$ & iniciam com o mesmo som? \\
\hline a) think & this & Não ([$[\theta]$ e $[ð]$, respectivamente). \\
\hline b) think & theater & $\operatorname{Sim}($ ambas com $[\theta])$. \\
\hline c) they & this & Sim (ambas com [ð]). \\
\hline d) think & fill & Não ([$[\theta]$ e $[f]$, respectivamente). \\
\hline e) that & dad & Não ([ð] e [d], respectivamente). \\
\hline
\end{tabular}

Fonte: Alves (2012, p. 181).

Tabela 3 - Reconhecimento da dicotomia 'alofones x pares mínimos' RECONHECIMENTO DE ALOFONES NA LÍNGUA MATERNA E PARES MÍNIMOS NA L2

Objetivo: através desta atividade de reflexão e análise, o aprendiz deverá concluir que, no inglês, os dois pares de sons em questão possuem caráter distintivo, enquanto que no português não.

\begin{tabular}{|c|c|}
\hline \multicolumn{2}{|c|}{$\begin{array}{l}\text { Ouça pares de palavras em inglês. As duas pronúncias que você ouvirá dizem respeito } \\
\text { à mesma palavra? }\end{array}$} \\
\hline a) cat $[\mathrm{t}] \quad$ catch $\left[\mathrm{t} \int\right]$ & Não \\
\hline b) deep $[\mathrm{d}] \quad$ jeep $[\mathrm{d} 3]$ & Não \\
\hline \multicolumn{2}{|c|}{$\begin{array}{l}\text { Agora ouça pares de palavras em português. As duas pronúncias que você ouvirá } \\
\text { dizem respeito à mesma palavra? }\end{array}$} \\
\hline c) tia $[\mathrm{t}]$ & Sim \\
\hline d) dia $[\mathrm{d}]$ & Sim \\
\hline
\end{tabular}


É provável que a manifestação dos níveis do desenvolvimento da $\mathrm{CF}$ se dê primeiro no reconhecimento de elementos menos complexos, como os silábicos e intrassilábicos e mais posteriormente com os fonêmicos e sons não distintivos, que requer um pouco mais de acurácia, embora, conforme Alves (op. cit.) não exista ainda um trabalho que comprove a ordem de desenvolvimento da CF em L2.

\subsection{A fricativa interdental surda do inglês $/ \theta /$}

A fricativa interdental surda do inglês $/ \theta /$ não compõe o inventário fonêmico do PB. Para Mascherpe (1970) e Othero (2005) a proximidade articulatória entre os segmentos linguísticos é umas das principais dificuldades no processo de percepção acústica. Ao ouvir palavras que contêm esse som, o falante brasileiro vai buscar no seu inventário o que mais se aproxima. Geralmente esse som é percebido como a fricativa labiodental surda /f/.

Ambos os fonemas, / $/ \theta /$ e /f/ para Ladefoged e Johnson (2011), compartilham propriedades acústicas muito semelhantes e a comprovação entre a produção de um ou outro requer do pesquisador uma análise mais acurada. Para que não houvesse qualquer tipo de dúvida nos resultados desta pesquisa, contamos com a análise acústica do programa computacional PRAAT versão 5.3 (BOERESMA; WEENINK, 2014).

\section{Metodologia}

A metodologia deste trabalho consistiu na gravação de uma frase em inglês lida por 01 falante norte-americano dos EUA. (que utilizamos como modelo de fala e apresentada na Fig. 1 da próxima seção unicamente para referência de pronúncia) e por 03 (três) alunos falantes nativos do PB. Os informantes são advindos de uma escola particular de nível regular ( $9^{\circ}$ ano) da cidade de Guarabira-PB.

A frase selecionada foi extraída de um texto em inglês, presente em um livro didático (AUN; MORAES; SANSANOVICZ, 2005), em que - além do trabalho realizado em sala de aula com questões interpretativas, morfológicas e sintáticas - contemplamos alguns aspectos fonético-fonológicos da L2. A frase selecionada para a gravação foi: What do you think of this blouse? Nesta frase-veículo, o segmento que serviu como palavra-chave foi a palavra think $/ \theta i \mathrm{k} /$, que apresenta o nosso objeto de estudo, a fricativa interdental surda. A frase foi apresentada em forma de flashcard em PowerPoint, em que foi dada nenhuma ênfase ortográfica ao segmento trabalhado.

Os alunos foram orientados a ouvir a frase ditada pela professora e após o estímulo acústico (pronunciada três vezes), eles deveriam repetir (também três vezes). A percepção da frase neste momento se deu na modalidade "pré-instrução" a qual indica que, formalmente, não se considera que houve contato fonético-fonológico do(s) segmento(s) por parte dos alunos. Nesta fase, o não-êxito é levado em conta pela falta de contato do aluno com a L2 em seus aspectos fonético-fonológicos. Denominamos esta etapa como primeira coleta.

Após esse momento da primeira coleta, em uma segunda aula, a produção da fricativa interdental surda foi destaque na aula de inglês. Os alunos tiveram contato com várias palavras que apresentavam o mesmo segmento, sendo instruídos de forma explícita acerca de sua articulação, recebendo também estímulos visuais de sua produção. Só depois deste momento foi realizada a etapa denominada segunda coleta com os mesmos informantes. Desta vez na modalidade "pós-instrução" a qual indica processos de CF e metalinguagem por 
parte dos alunos. Nesta fase, o êxito é levado em conta pela instrução explicita trabalhada pelo professor em sala de aula.

Para a coleta de dados utilizamos um gravador Zoom H1 Handy Recorder 200m. O momento da coleta também foi planejado. Escolhemos um horário em que todos os alunos da escola haviam saído e nos direcionamos à biblioteca. Após coletadas, ambas as gravações foram rodadas e analisadas acusticamente no programa computacional PRAAT versão 5.3 (BOERSMA; WEENINK, 2014).

\section{Análise dos dados}

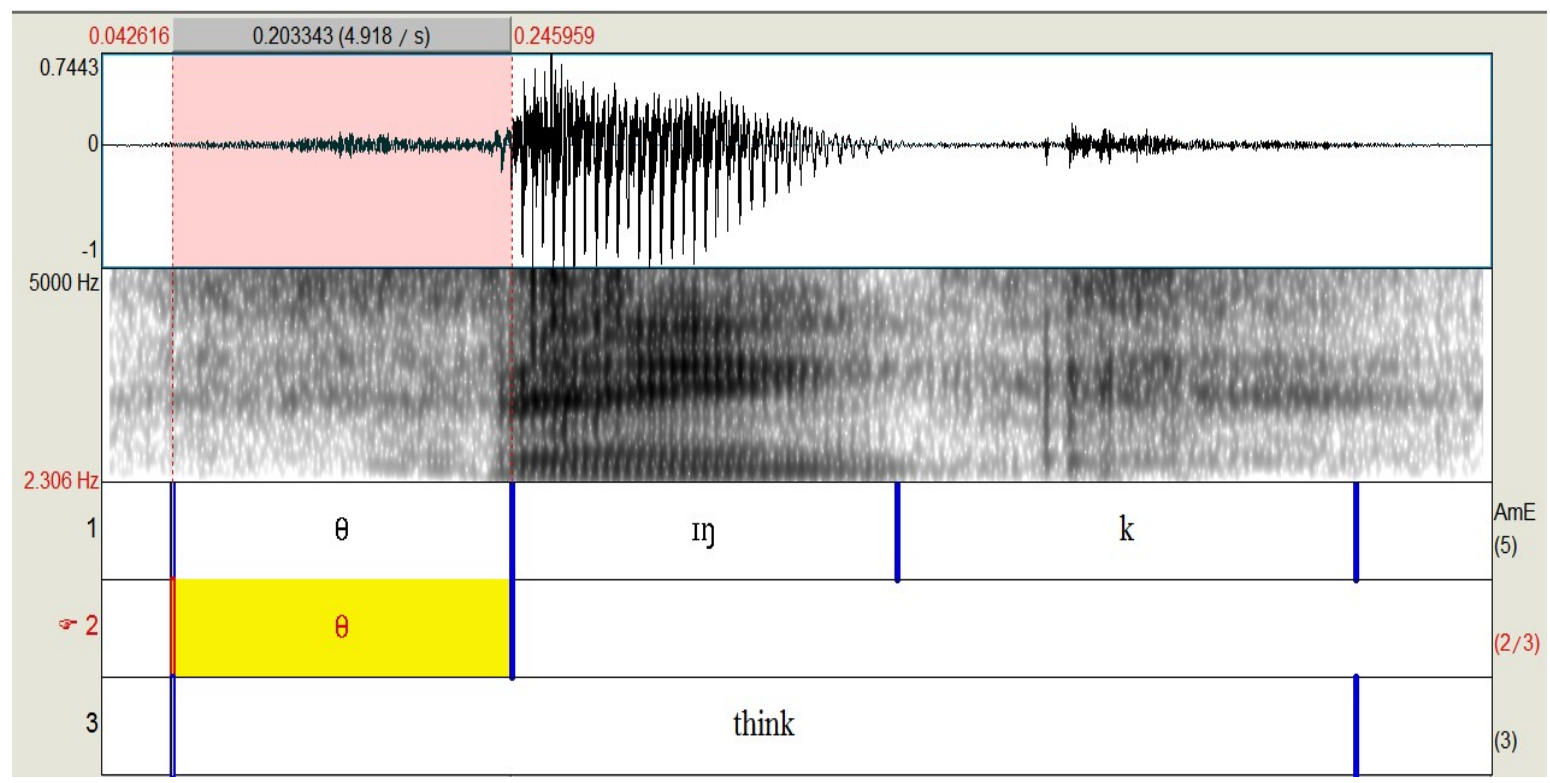

Figura 1: Produção do falante norte-americano da palavra "think" com destaque em amarelo para fricativa interdental surda $[\theta]$.

Fonte: Elaboração dos autores.

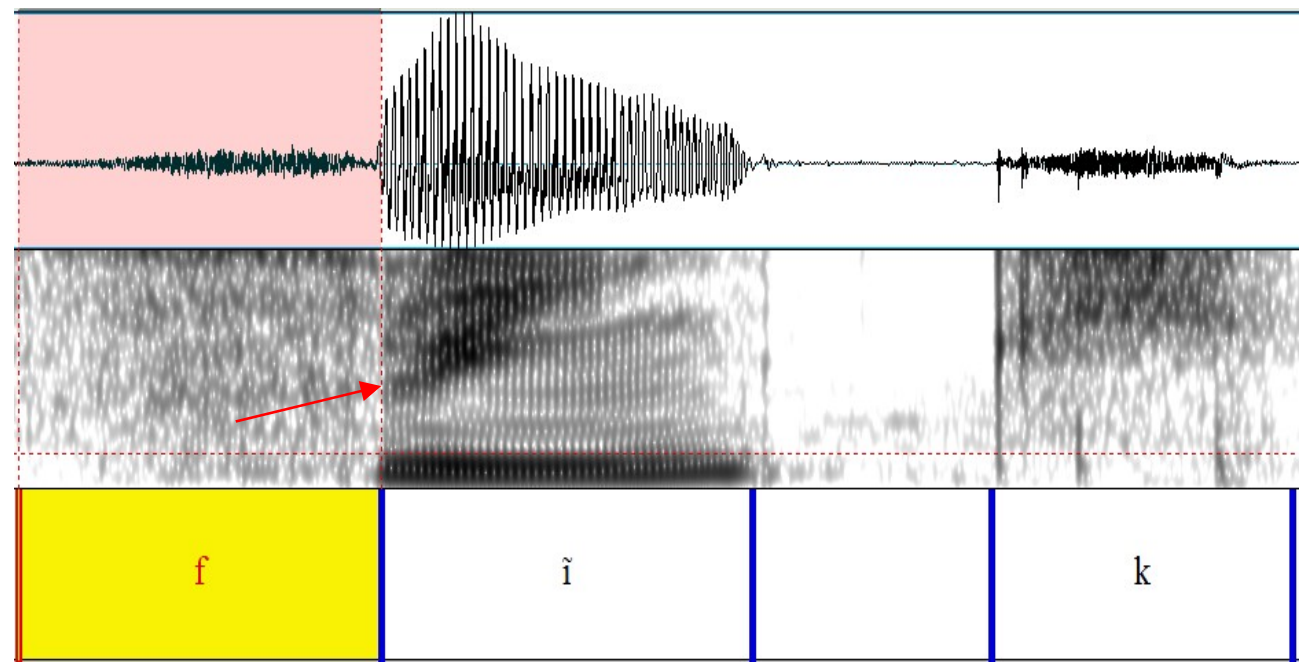

Figura 2 - Produção pré-instrução com substituição da fricativa interdental surda $\{\theta]$ pela fricativa labiodental surda [f] na palavra "think”.

Fonte: Elaboração dos autores. 
Conforme já destacado nos pressupostos teóricos, a fricativa interdental surda do inglês $/ \theta$ / e a fricativa labiodental surda do PB /f/ apresentam propriedades acústicas muito semelhantes, de forma que visualmente, fica praticamente impossível detectar a presença de um em detrimento do outro.

Para que não houvesse dúvidas em nossas análises, recorremos ao trabalho monográfico de Alves (2016) que utiliza como suporte para identificar a produção de ambos os segmentos os estudos de Ladefoged e Johnson (2011). Os autores afirmam que tanto o fone [ $\theta$ ] como o [f] compartilham padrões acústicos semelhantes. A técnica utilizada por Alves (2016) - proposta por Ladefoged e Johnson (op. cit.) - para determinar o contraste fônico toma como base o valor do segundo formante (doravante, F2) do núcleo silábico.

Em fonética acústica o termo formante é designado quando há a presença de ondas estacionárias. Conforme Barbosa e Madureira (2015), para que haja a formação dessas ondas é necessário que duas ondas de mesma fase se encontrem no trato vocal. Quando produzimos qualquer som, há uma fonte geradora de energia. Na maior parte dos fonemas do PB as pregas vocais é a fonte mais comum, apenas as obstruintes surdas não utilizam essa fonte como geradora de energia. Ao pensar nas pregas vocais como fonte, ao produzir uma vogal, por exemplo, a energia localizada perto dessa fonte no momento da produção encontra-se em repouso. Ao se deslocar pelo trato vocal, essas partículas vão irradiar até a saída (lábios) onde estarão em velocidade máxima. Essa ação vai provocar uma reação nas partículas de ar que estão fora do trato, ambiente externo, e provocam como reação o retorno da onda à fonte. Nesse retorno, ao encontrar uma onda de mesma fase, as duas pressões sonoras, que nesse momento atingem seu máximo, se unem e essa pressão dobra. Essa onda, com pressão dobrada continua a se propagar no trato e com isso dizemos que houve ressonância (formação de ondas estacionárias).

A grande maioria dos sons do PB possui formantes. Apenas segmentos bilabiais não apresentam a formação formântica pelo fato de serem articulados na saída do trato vocal (lábios) e com isso não permite que as ondas façam esse percurso de entrada e saída de deslocamento de ar. Os formantes são identificados pelos seus números. Há infinitos formantes, mas para as análises, é suficiente utilizar os três primeiros que são identificados como F1, F2 e F3. A seguir explicaremos por que em nossas análises, utilizamos o segundo formante do núcleo silábico para determinação da fricativa.

Ladefoged e Johnson (op. cit.) estabelecem como valor para essa vogal alta coarticulada [ĩ] que sua F2 $\approx 1800 \mathrm{~Hz}$. O estabelecimento da medida da F2 como parâmetro se dá pelo fato deste formante possuir as propriedades de antero-posterioridade do segmento. $\mathrm{Ou}$ seja, caso a energia da fricativa seja menor que $1800 \mathrm{~Hz}$, teremos a produção de uma labiodental (vide Fig. 2), caso o valor da energia da fricativa supere $1800 \mathrm{~Hz}$, teremos a produção de uma interdental (vide Fig. 1).

O que faz a labiodental ter uma energia levemente mais baixa é devido ao ponto de obstrução deste segmento ser realizado na abertura do tubo ressoador (lábios e dentes) o que vai gerar uma maior extensão para propagação das partículas de energia, onde elas estarão mais difundidas, com o mínimo possível de concentração. Como as interdentais têm uma obstrução um pouco mais posterior, a extensão do tubo ressoador terá uma leve redução e em comparação com as labiodentais, a concentração de energia terá um leve aumento.

Na Fig. 2 podemos comprovar a produção da fricativa labiodental [f], pelo fato de termos encontrado o valor do núcleo silábico da $\mathrm{F} 2$ em torno de $1500 \mathrm{~Hz}$ como mostra a indicação na figura, o que comprova uma extensão maior do tubo ressoador no momento da articulação. 


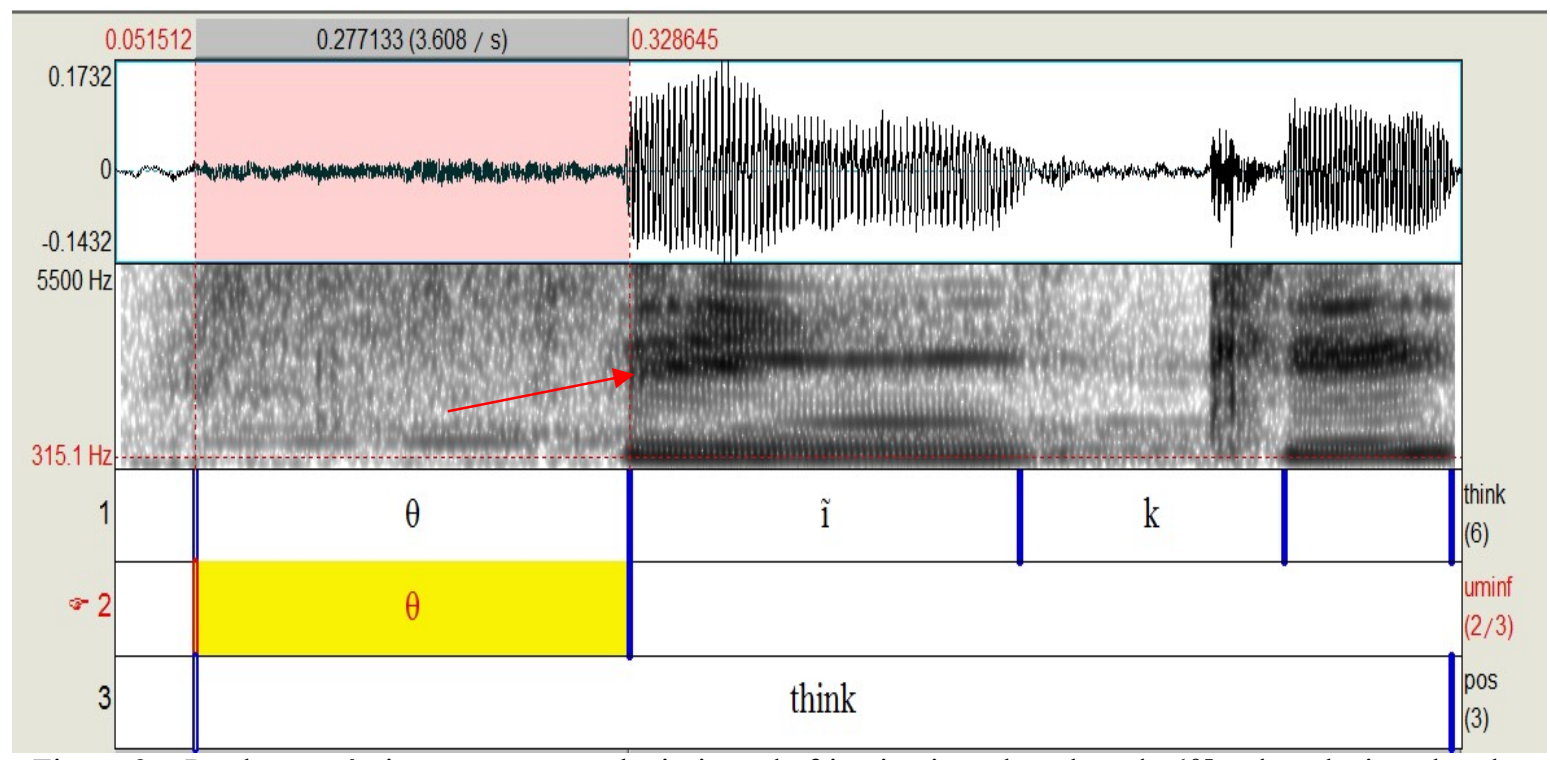

Figura 3 - Produção pós-instrução com substituição da fricativa interdental surda $\{\theta]$ pela oclusiva alveolar surda [t] na palavra "think".

Fonte: Elaboração dos autores.

Na segunda coleta (Fig. 3), após instrução de como se dá a realização do segmento almejado, obtivemos como valor de F2 para o núcleo silábico da palavra think uma medida acima de $2000 \mathrm{~Hz}$ como mostra a indicação na figura. Esse valor comprova a produção da fricativa interdental surda do inglês.

Também na segunda coleta, atestamos a substituição de fricativa interdental surda [ $\theta]$ não mais por outra fricativa - como [f] - mas sim, pela uma oclusiva alveolar [t] destacada em amarelo no espectrograma como mostra a Fig. 4.

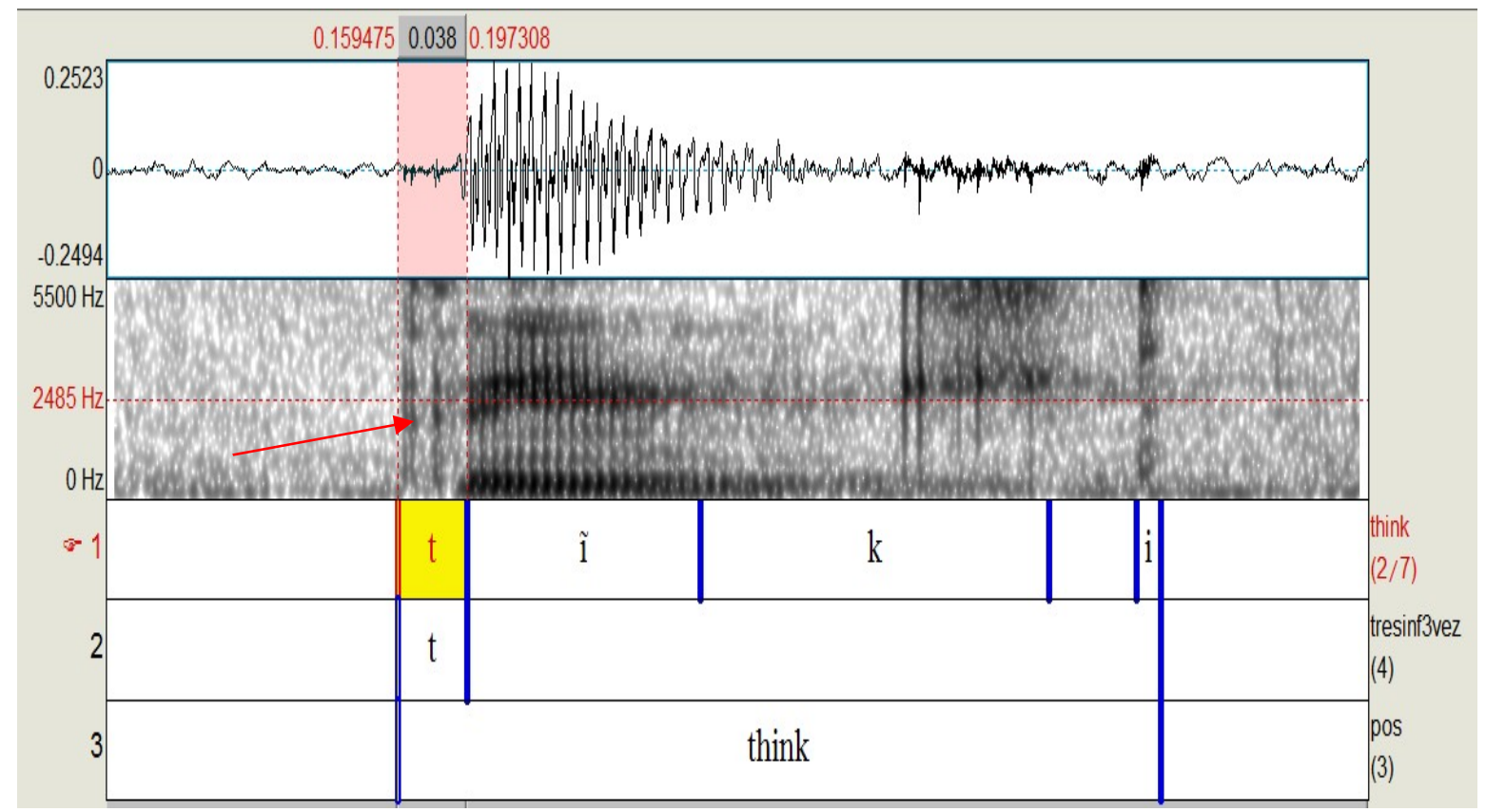

Figura 4 - Produção pós-instrução da fricativa interdental surda do inglês [ $\theta$ ] na palavra “think".

Fonte: Elaboração dos autores. 
As oclusivas alveolares (nesta pesquisa o som [t]) em posição de ataque silábico possuem características acústicas que são mapeadas em três fases distintas: fase de fechamento (período silencioso antes da transição), fase transiente (momento que imediatamente antecede a soltura) e fase de soltura (explosão de ar que antecede o núcleo vocálico também denominado, voice onset time - VOT) como mostra a indicação na figura (cf. BARBOSA; MADUREIRA, 2015; LADEFOGED; JOHNSON, 2011; JONGMAN; BLUMSTEIN, 1985).

A partir das análises acústicas aqui realizadas, apresentamos a quantificação dos resultados (\%) no Gráfico 1 que indicam o quanto a instrução monitorada pode contribuir para uma produção fonética inteligível do segmento em estudo.

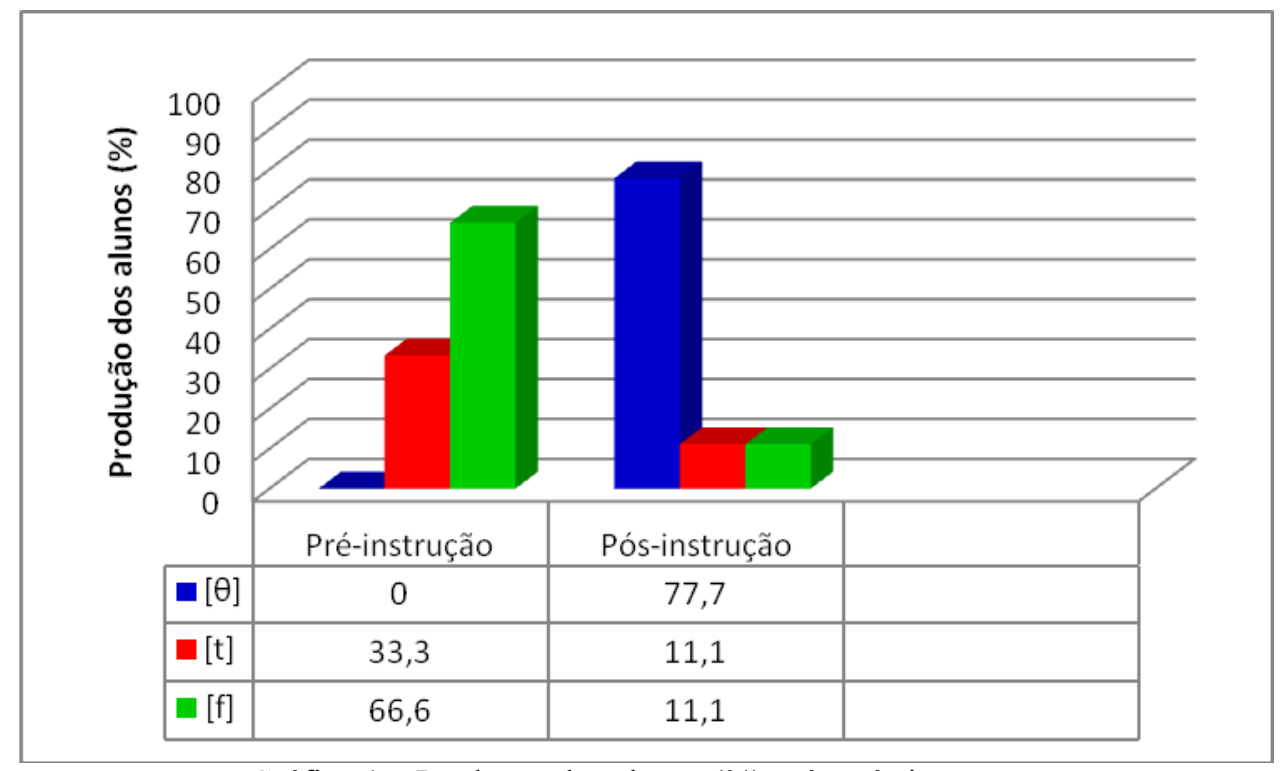

Gráfico 1 - Produção dos alunos (\%) pré e pós instrução.

Fonte: Elaboração dos autores.

Embora não possamos garantir que esses alunos internalizaram de fato as diferenças fonêmicas trabalhadas em sala de aula, a ponto de produzirem esse segmento em situações não monitoradas, concluímos que esse tipo de abordagem não deve ser discriminada quando trata-se de trabalhar uma nova língua. É importante que o professor não negligencie as habilidades orais, sobretudo quando o sistema linguístico ao qual esteja trabalhando, como o inglês, apresenta distinções fonêmicas diferentes da L1.

Silva Jr. (2014) aponta a importância de um trabalho em L2 tendo como pré-requisito as habilidades de listening e speaking. Quanto mais o aluno é exposto à língua, mais chances ele terá de internalizar os parâmetros pertencentes a ela.

A partir das análises acústicas aqui realizadas, a quantificação dos resultados (\%) apresentam-se no Gráfico 1.

\section{Conclusão}

Através dos dados obtidos na pesquisa, foi possível perceber que o PB é o caminho linguístico que os estudantes utilizam para tratar a língua inglesa no contexto da oralidade e que a carência do estímulo acústico contribui de forma significativa para realização de processos de TF.

Esperamos com essa pesquisa mostrar a relevância de tais conhecimentos no ensino de inglês como L2, visto que ao saber o porquê de determinados desvios dos padrões 
fonético-fonológicos, fica mais fácil encontrar uma solução que venha na menor das possibilidades, amenizar tais problemas. Assim, tendo em mãos essa capacidade, o profissional levará para o aprendiz a possibilidade de adquirir um melhor desempenho das habilidades orais (percepção e produção dos sons da língua) no sistema comunicacional da L2, corroborando o pensamento de Vasseur (2015), ao afirmar que, no processo de aquisição da L2, é importante compreender como o indivíduo aprende para que assim o profissional possa compreender o desenvolvimento da competência em interagir em L2.

O pouco tempo de exposição à língua, até mesmo por parte do professor, que na maioria das vezes utiliza a L1 para ensinar a L2, não favorece a discriminação das diferenças encontradas entre os sistemas linguísticos no tocante à fonética e à fonologia. Desta forma, é importante que aos poucos o aprendiz tenha consciência de tais distinções. Um ensino que leva em conta o desenvolvimento da CF em L2 leva, na menor das hipóteses, a um esclarecimento das próprias dificuldades do indivíduo para que este possa refletir e manipular os novos sons aprendidos.

Conforme discutimos, o trabalho envolvendo o desenvolvimento dos aspectos fonológicos do inglês não precisa ser encarado como tarefa complexa. Exercícios simples, atrelados ao cotidiano escolar dão conta de levar o aprendiz a perceber aos poucos tais distinções. Tratando-se de um público adolescente, como o aqui exposto, quanto mais o professor transformar a abordagem num momento dinâmico, divertido, mais próximo e motivado o aluno vai estar da língua-alvo. Exercícios simples, atrelados ao cotidiano escolar dão conta de levar o aprendiz a perceber aos poucos distinções entre a L1 e L2. Tratando-se de um público adolescente, como o aqui exposto, quanto mais o professor transformar a abordagem em um momento dinâmico e motivador, maiores as chances de o aluno produzir a língua-alvo (cf. ELLIS, 1994, p. 294-295).

É importante que o professor encare não só o ensino da gramática, ampliação de vocabulário e interpretação textual como fundamentais durante a realização do seu trabalho, mas compreenda que os aspectos fonético-fonológicos não podem ser negligenciados ao aluno, visto que é através deles que todos os demais aspectos linguísticos se constituem. Devido à complexidade de algumas distinções, como por exemplo, perceber que determinado fonema não é o mesmo da L1 do aprendiz, é interessante que o professor tenha essa contribuição para o desenvolvimento da CF do aluno.

\section{Referências}

ALVES, U. K. Consciência dos aspectos fonético/fonológicos da L2. In: LAMPRECHT, R. R.; BLANCO-DUTRA, A. P. et al. (Orgs.). Consciência dos sons de língua: subsídios teóricos e práticos para alfabetizadores, fonoaudiólogos e professores da língua inglesa. Porto Alegre: EDIPUCRS, 2012, p. 170-192.

ALVES, A. C. A importância da consciência fonológica na aquisição do inglês como segunda língua. Guarabira, 2016. 53f. Trabalho de conclusão de curso (Graduação em Letras) - Universidade Estadual da Paraíba.

AUN, E.; MORAES, M. C. P. de; SANSANOVICZ, N. B. Get together at the new English point, 3. 1. ed. São Paulo: Saraiva, 2005, p. 16.

BOERSMA, P.; WEENINK, D. Praat: doing phonetics by computer (Version 5.3). Disponível em: $<$ http//www.praat.org $>$ Acesso em: ago. 2014. 
ELLIS, R. The study of second language acquisition. Oxford: Oxford University Press, 1994.

HAYES, B. Introductory phonology. Malden: Wiley-Blackwell, 2009.

JENKINS, J. English as a lingua franca: attitude and identity. Oxford: Oxford University Press, 2007.

JENKINS, J. The phonology of English as an international language: new model, new norms, new goals. Oxford: Oxford University Press, 2000.

JONGMAN, A.; BLUMSTEIN, S. Acoustic properties of dental and alveolar stop consonants: a cross-language study. Journal of phonetics, Providence, v 13, p. 235-251, 1985.

KRAMSCH, C. Context and culture in language teaching. Oxford: Oxford University Press, 1993.

LADEFOGED, P.; JOHNSON, K. A course in phonetics. 6 ed. Boston: Wadsworth, 2011.

MASCHERPE, M. Análise comparativa dos sistemas fonológicos do inglês e do português. Assis, 1970. 156f. Tese (Doutorado em Letras) - Faculdade de Filosofia, Ciências e Letras de Assis.

OTHERO, G. A. Processos fonológicos na aquisição da linguagem pela criança. ReVEL, Rio de Janeiro, v. 3, n. 5, p. 1-13, 2005.

POLIVANOV, E. La perception des sons díune langue Ètrangère. Travaux du Cercle Linguistique de Prague, Prague, v. 4, 1931, p. 79-96. [Tradução para o inglês: The subjective nature of the perceptions of language sounds. In: POLIVANOV, E. Selected works: articles on general linguistics. Mouton, The Hague, 1974, p. 223-237].

RAMOS, E. Transferência fonológica no ensino de língua inglesa. In: LIMA, D. C. de. (Org.). Ensino aprendizagem de língua inglesa: conversas com especialistas. São Paulo: Parábola Editorial, 2009, p. 53-58.

SILVA Jr, L. J. O ensino de pronúncia na formação do aluno de letras: contribuições da habilidade listening. In: IV Encontro de iniciação à docência (ENID), 2014, Campina Grande. Anais... Campina Grande: UEPB, 2014. p. 1-5. Disponível em: $<$ http://www.editorarealize.com.br/revistas/eniduepb/anais. php>. Acesso em: 08 mar. 2015.

VASSEUR, M-T. Aquisição da L2: compreender como se aprende para compreender o desenvolvimento da competência em interagir em L2. In: DEL RÉ, A. (Org.). Aquisição da linguagem: uma abordagem psicolinguística. 2. ed., 3 reimp. São Paulo: Contexto, 2015, p. 85-111.

WIDDOWSON, H. G. Teaching language as communication. Oxford: Oxford University Press, 1978.

Recebido em: julho de 2017.

Aprovado em: agosto de 2017. 